\title{
Acne Treatment with Minocycline, Not So Innocent
}

\author{
Pale C, Vigna L, Cuesta M, Bresan E, Méndez J, Torn A and Sotelo C
}

Sanatorio Las Lomas, Internal Medicine, San Isidro, Buenos Aires, Argentina

*Corresponding author: Carlos Alberto Pale, Chief of Internal Medicine, Sanatorio Las Lomas, Internal Medicine, Carman 555, San Isidro, Buenos Aiers 1642, Argentina, Tel: 0541141295500; E-mail: cpale@laslomas.com.ar

Rec date: May 07, 2014 Acc date: Jan 14, 2015 Pub date: Jan 20, 2015

Copyright: (c) 2015 Carlos Alberto Pale. This is an open-access article distributed under the terms of the Creative Commons Attribution License, which permits unrestricted use, distribution, and reproduction in any medium, provided the original author and source are credited.

\section{Background}

Minocycline is commonly prescribed for the treatment of acne vulgaris. Drug reaction with eosinophilia and systemic symptoms (DRESS) syndrome is a severe drug-induced reaction associated with a variety of medications, including minocycline.

Here, we present a clinical case of minocyclin induced DRESS syndrome.

\section{Case Report}

A 17 year-old-female patient was admitted because of fever, rash, pneumonitis and lymphadenopathies, which were present since 5 days prior admission.

Her medical history was unremarkable, except for acné vulgaris, being treated with Minocyclin for the last 3 weeks.

She reported dry cough, asthenia and fatigue. Physical examination revealed $40^{\circ} \mathrm{C}$ fever, cervical lymphadenopaties and splenomegaly, along with maculopapular eruption that involved the entire body.

Chest roentgenogram revealed bilateral interstitial infiltrates.

Mononucleosis was ruled out and blood cultures yielded negative results.

Lymph node biopsy revealed nodular hyperplasia.

With the assumption that the syndrome was caused by minocycline hypersensitivity, the patient was treated with dexamethasone (24 $\mathrm{mg} / \mathrm{ml}$ daily). Her symptoms improved and she was discharged.

Two months later, she was admitted again because of severe dermatitis with large areas of desquamation, along with marked facial swelling, eosinophilia and renal impairment. By this time, the patient was still on corticosteroids treatment (prednisone $30 \mathrm{mg} /$ day).
Her WBC was $12.8 \times 10^{9} / \mathrm{L}$ (Lymphocytes $42 \%$, eosinophils $26 \%$ ), urea $112 \mathrm{mg} / \mathrm{dL}$, creatinine $1.8 \mathrm{mg} / \mathrm{dL}$, AST $37 \mathrm{UI}$, ALT $152 \mathrm{UI}$

A skin biopsy revealed lymphocytic perivascular infiltrate.

Prednisone dose was increased up to $1.5 \mathrm{mg} / \mathrm{kg} /$ day and IV Ig 3 $\mathrm{gr} / \mathrm{kg} /$ total dose was administered. Her condition slowly improved and was discharged.

Follow up 2 month later revealed only residual hyper pigmented lesions in trunk.

\section{Discussion}

We report a patient with fever, lymphadenophathy, rash and pneumonitis occurring after a minocycline treatment. In spite of corticosteroids treatment, the patient developed severe exfoliative dermatitis, eosinophilia and systemic involvement. In light of the similarity with other previously reported cases, we assume that this case relates to a DRESS syndrome.

Minocycline has been found to be infrequently associated with DRESS and its pathogenesis is partially understood. Several mechanisms have been described, such as T-cell activation.

Several of our patient's signs and symptoms, including the severe dermatitis with lymphocytic skin infiltrate suggest $\mathrm{T}$ cell activation involvement. The fact that the accumulation of minocycline in the skin is long lasting could explain the relapse in our patient that merited her re-admission.

High dose of IVIg represents an important therapeutic option in patients who do not improve in spite of corticosteroid treatment.

We believe that the early detection of DRESS in clinical practice is of extreme importance due to its potential life- threatening nature. 